\title{
Electron Microprobe Analysis of Human Labial Gland Secretory Granules in Cystic Fibrosis
}

\author{
Kenneth Izutsu, Dale Johnson, Mark Schubert, Eunice Wang, Bonnie Ramsey, Amold Tamarin, Edmond Truelove, \\ Wayne Ensign, and Mark Young \\ Departments of Oral Medicine and Oral Biology, School of Dentistry and Center for Bioengineering, and Department of Pediatrics, \\ The University of Washington, and The Childrens Orthopedic Hospital and Medical Center, Seattle, Washington 98195
}

\begin{abstract}
X-ray microanalysis of freeze-dried labial gland cryosections revealed that $\mathrm{Na}$ concentration was doubled and the $\mathrm{Ca} / \mathrm{S}$ concentration ratio was decreased in secretory granules of labial glands from patients with cystic fibrosis (CF) when compared with glands from normal subjects. Other results suggested that the decrease in the $\mathrm{Ca} / \mathrm{S}$ concentration ratio resulted from an increase in $\mathrm{S}$ concentration. These findings imply that mucous granules in labial saliva showed a CFrelated increase in $\mathrm{Na}$ and $\mathrm{S}$ content, and such changes would be expected to affect the rheology of the mucus after exocytosis. In contrast with a previous study in human parotid glands, no evidence was found for CF-related changes in cytoplasmic or nuclear $\mathrm{Na}, \mathrm{K}$, and $\mathrm{Ca}$ concentrations. Significant elemental differences were found between secretory granules and nuclei and cytoplasm of control cells.
\end{abstract}

\section{Introduction}

Mucus is of interest to many investigators who study cystic fibrosis $(C F)^{1}$ because of its central role in the bronchial pathology of the disease. One of the difficulties in studying CF-related changes in mucus physiology has been the lack of a convenient experimental preparation. We propose the human labial salivary gland as a model for such studies. Several factors contribute to this choice. First, labial salivary glands consist primarily of mucous acini (1), and thus may serve as models for mucous glands of the tracheal-bronchial tree. Second, labial glands are affected in $\mathrm{CF}$, as indicated by the disease-related increase in labial saliva $\mathrm{Na}$ concentration (2) and by histopathological findings $(3,4)$. Third, the glands are easily available by labial biopsy. In addition, we now present evidence that labial gland mucous granules showed a disease-related increase in sodium content and highly suggestive evidence for an increased sulfur content. Both these changes could alter the rheological properties of mucus, and so could affect its transport in vivo $(5,6)$. Additionally, the present results allow us to test whether the marked CF-related changes in elemental concentrations previously reported in human parotid glands (7) occur in human labial glands, and to determine the subcellular distributions of any such changes. Finally, the present report

Received for publication 10 October 1984 and in revised form 29 January 1985.

1. Abbreviation used in this paper: CF, cystic fibrosis.

J. Clin. Invest.

(c) The American Society for Clinical Investigation, Inc. 0021-9738/85/06/1951/06 \$1.00

Volume 75, June 1985, 1951-1956 is the first to give intracellular elemental concentrations for a human salivary gland using the microprobe method.

\section{Methods}

The X-ray microanalysis technique was used to test for CF-related increases in $\mathrm{Na}, \mathrm{S}, \mathrm{Cl}, \mathrm{K}$, and $\mathrm{Ca}$ contents of secretory granules from human labial glands.

Subjects. Volunteers with CF were admitted to this study if they fulfilled at least two of the following criteria: $(a)$ a sweat $\mathrm{Cl}$ concentration $>60 \mathrm{mM}$ by quantitative pilocarpine iontophoresis, $(b)$ evidence of chronic obstructive pulmonary disease (i.e., abnormal chest X-ray or abnormal pulmonary function test), and (c) evidence of exocrine pancreatic insufficiency. Disease severity was evaluated using the scores (i.e., NIH scores) proposed by Taussig et al. (8). Pulmonary function was evaluated using functional vital capacities as obtained from clinical records.

Normal volunteers were admitted to this study if they were caucasian, $<30 \mathrm{yr}$ of age, and in excellent health.

All participants received financial compensation, and all procedures were approved by the University of Washington Human Subjects Committee, Seattle, WA.

Labial gland fragments. Labial salivary gland fragments between 1 and $2 \mathrm{~mm}$ in length were obtained from the lower inner lip under standard dental anesthetic conditions. Gland fragments were excised and either placed in formalin for light microscopy or positioned on stainless steel chucks so as to decrease the likelihood of sampling dissected cells. The samples were frozen by quick immersion in rapidly stirred Freon $22\left(-156^{\circ} \mathrm{C}\right.$; Thermal Supply, Seattle, WA) cooled with liquid nitrogen.

A cryoultramicrotome (model MT2-B; E. I. Du Pont de Nemours \& Co., Inc./Sorvall Instruments Div., Newtown, CT) was used to prepare thin sections. The cold bowl temperature was maintained at $-100^{\circ} \mathrm{C}$. A knife clearance angle of $7^{\circ}$ and lowest cutting speed were used. Dry cut sections were transferred to copper double grids coated with formvar (Ladd Research Industries, Burlington, VT) and carbon films, and freeze-dried overnight at $10^{-5}$ torr in a high vacuum evaporator (Edwards High Vacuum, Inc., Grand Island, NY). Grids were stored in a desiccator until analyzed.

Elemental analysis. The freeze-dried sections were examined in an electron microscope (model 100C; JEOL USA, Electron Optics Div., Peabody, MA). All $x$-ray spectra were collected in the scanning transmission mode at $20^{\circ} \mathrm{C}$. A square raster $1,000 \AA$ on a side, with a beam current of $10^{-8} \mathrm{~A}$ and a counting time of $200 \mathrm{~s}$ for a total specimen dose of $\sim 2 \times 10^{4} \mathrm{C} / \mathrm{cm}^{2}$ were typically used. Specimens were tilted toward the detector at an angle of $45^{\circ}$ from the incident beam, and the area analyzed was about $2 \mathrm{~cm}$ from the detector. Analyses were made with the folding grids opened after freeze-drying, and the specimen continuum count corrected for the continuum contribution of a single support film. Emitted $\mathrm{x}$ rays from various cell structures were detected with a $30 \mathrm{~mm}^{2} \mathrm{Si}(\mathrm{Li})$ crystal, and $\mathrm{x}$-ray energy spectra were generated with a pulse height analyzer (model 7000; Kevex X-ray Tube Div., Kevex Corp., Scotts Valley, CA). The spectra were analyzed with a dedicated PDP-11 microcomputer (Digital Equipment Co., Marlboro, MA) using a digital filtration and least squares fitting program (9). The analysis uses the ratio of peak counts to continuum (1.00-3.90 keV in our case) count to calculate elemental 
mass fractions as described by Hall et al. (10). Binary salt standards were used to establish relative counting efficiencies, and $S$ in an albumin sample was used as an absolute standard. The remaining absolute proportionality constants were then obtained using the relative proportionality constants. The resulting concentrations and patient information were stored and analyzed in a CDC Cyber 170-750 mainframe computer (Control Data Corp., Minneapolis, MN).

Elemental concentrations from patients and controls were compared using several statistical procedures: the oneway analysis of variance with linear contrast by disease status, the unpaired $t$ test between means of means for each subject segregated by disease status, and the nonparametric Mann-Whitney $U$ rank test (11). The first of the above parametric tests was included primarily for comparative purposes. The only previous quantitative application of the microprobe method to the study of CF used the $t$ test over all values (which is equivalent to the oneway analysis of variance when there are two groups) to test for disease-related changes in elemental concentrations of cultured fibroblasts (12). The nonparametric rank test was included since it is appropriate for small sample numbers and is less sensitive to the effect of extreme values than the parametric tests.

A disease-related difference in $\mathrm{Ca} / \mathrm{S}$ concentration ratio was also investigated. This elemental ratio has advantages over the absolute concentrations because it is independent of sources of errors such as continuum measurement and film correction which are used in calculating the absolute elemental concentrations $(9,10)$. Specifically, when calculated concentrations for a given spectrum are expressed as a ratio, the sample continuum counts that are the same for both elements cancel out, leaving only the ratio of elemental counts; i.e. from reference 10: $\left(\right.$ concentration $\left.X_{1}\right) /\left(\right.$ concentration $\left.X_{2}\right)=($ elemental counts $X_{1} /$ sample continuum counts)/(elemental counts $X_{2} /$ sample continuum counts $)=\left(\right.$ elemental counts $\left.X_{1}\right) /\left(\right.$ elemental counts $\left.X_{2}\right)$. Thus, the concentrations ratios are based on fewer measured variables and require fewer calculations than the concentrations themselves. Hence, they are more precise. The only inconvenience in the use of such ratios is that the interpretation of changes in them is not as simple as for concentration changes.

Elemental concentration differences between organelles in control cells were examined using the oneway analysis of variance on the means of means and Duncan's method for least significant differences. The findings from the analysis of variance were confirmed by the Kruskal-Wallis nonparametric oneway analysis of variance which was required since the data did not meet (and could not be transformed to meet) the requirements for homoscedasticity (13).

Correlations between the elemental concentrations and the various experimental parameters (e.g., film continuum counts, Chi square of fit, $\mathrm{Cu}$ count, etc.) were tested using the regression routine (13).

Mass loss during beam exposure was evaluated in a separate series of experiments using a series of 25-s (live time) counts for each of the elements and the continuum. The initial count was typically obtained with a dose of about $2.6 \times 10^{-4} \mathrm{C} / \mathrm{cm}^{2}$, and the final accumulated dose was about $2.7 \times 10^{3} \mathrm{C} / \mathrm{cm}^{2}$. Care was taken to monitor for contamination, sample drift and shrinkage, and current drift. Mass loss was evaluated by regressing continuum (or specific elemental) counts against dose. All tests were done using the Statistical Package for the Social Sciences (13).

\section{Results}

$C F$ patients. Six patients (five males and one female) with $C F$ from the Cystic Fibrosis Center at Children's Orthopedic Hospital and Medical Center (Seattle, WA) volunteered for this study. All patients were between 18 and $30 \mathrm{yr}$ of age and had a wide range of disease severity (NIH scores, 35-85). All patients were colonized with Staphylococcus aureus and/or Pseudomonas aeruginosa (Table I).

All six patients had taken an enteric-coated enzyme product and fat soluble vitamin supplements for many years. They also received a variety of antibiotics. Patients with only $S$. aureus colonization had received either Cephalexin or dicloxacillin in the previous year. Patients with $P$. aeruginosa colonization had received oral trimethoprimsulfamethoxazole, tetracycline, or intravenous aminoglycosides and a urido penicillin in the previous year.

Only two patients used bronchodilators: patient 8 , theophylline and metaproteronal; patient 7 , metaproteronal. These two patients also used antacids periodically. Patient 8 received morphine sulfate and meperidine for severe headaches.

Controls. Five normal, healthy subjects (two males and three females) between 21 and $30 \mathrm{yr}$ of age volunteered for the study.

All subjects tolerated the biopsy procedure well. Approximately half reported soreness of several days' duration. A $24-$ $h$ telephone number was available in case of discomfort, but no calls were received, and all cases healed without incident.

Electron microscopy of freeze-dried cryosections. Acinar cells were frequently observed in the freeze-dried cryosections, but duct cells were not (Fig. 1). Intracellular and extracellular spaces were clearly discernible. Nuclear and cytoplasmic regions were also discernible, as were secretory granules. At least a few secretory granules were observed in nearly all cells. Only electron dense secretory granules were selected for study.

Table I. Clinical Findings in Patients with CF

\begin{tabular}{|c|c|c|c|c|c|c|c|}
\hline $\begin{array}{l}\text { Patient } \\
\text { code }\end{array}$ & Sex & Age & $\begin{array}{l}\text { Sweat } \\
\text { (Cl) }\end{array}$ & NIH score & $\begin{array}{l}\text { Functional vital capacity } \\
\text { (percent predicted values) }\end{array}$ & $\begin{array}{l}\text { Bacteriology } \\
\text { of sputum }\end{array}$ & $\begin{array}{l}\text { Medication used in } \\
\text { previous year }\end{array}$ \\
\hline & & $y r$ & $m M$ & & & & \\
\hline 6 & $\mathbf{M}$ & 18 & 138 & 50 & 47 & A, B & $1,2,6$ \\
\hline 7 & $\mathbf{M}$ & 20 & 134 & 70 & 59 & B & $1,2,5$ \\
\hline 8 & $\mathbf{M}$ & 30 & 107 & 35 & 52 & A, B & $1-9$ \\
\hline 9 & $\mathbf{M}$ & 21 & 123 & 76 & 75 & A, B & $1,2,4,6,9$ \\
\hline 10 & $\mathrm{~F}$ & 25 & 116 & 85 & 93 & $\mathrm{~A}, \mathrm{~B}, \mathrm{C}$ & $1,2,6$ \\
\hline 11 & $\mathbf{M}$ & 21 & 90 & 88 & 90 & B & $1,2,5$ \\
\hline
\end{tabular}

A, Pseudomonas aeruginosa; B, Staphylococcus aureus; C, Pseudomonas cepacia; 1, enteric coated enzyme product; 2 , fat soluble vitamin supplement; 3, theophylline; 4, metaproteronal; 5, anti-staphylococcal antibiotics; 6, anti-pseudomonas antibiotics; 7, demerol; 8, morphine; 9, antacids; F, female; and $M$, male. 


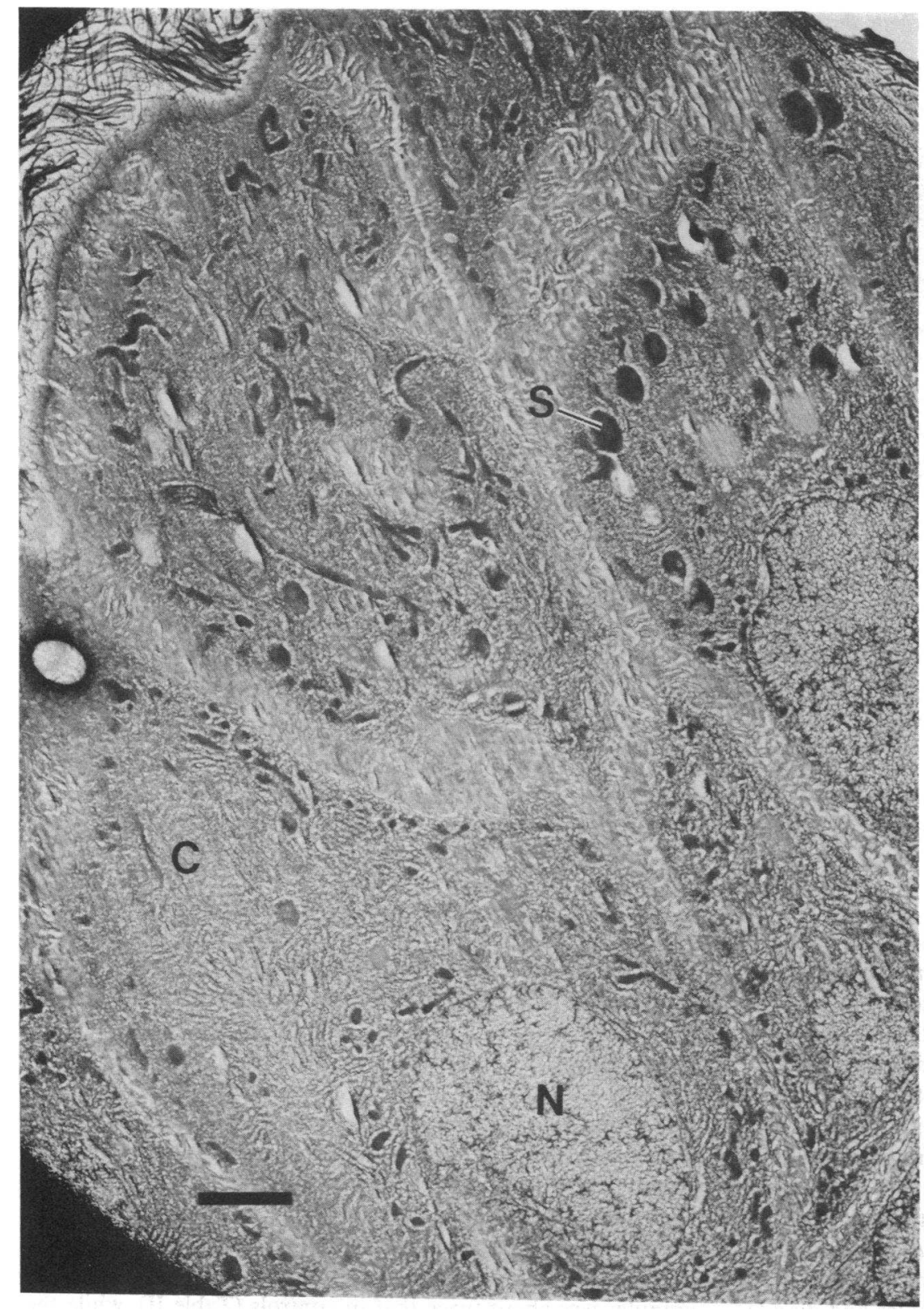

Figure 1. A freeze-dried, unstained cryosection of human labial gland. Nuclear $(\mathrm{N})$ and cytoplasmic $(\mathrm{C})$ areas were readily discernible. Electron dense secretory granules (S) similar to those in the cell at the middle right of the figure were sampled in this study. A $2-\mu \mathrm{m}$ bar is shown at the bottom left edge.
Elemental analysis. The electron beam raster area could readily be adjusted to include the selected structures. X-ray spectra from secretory granules consisted primarily of $\mathrm{P}, \mathrm{S}, \mathrm{Cl}$, $\mathrm{K}$, and Ca peaks (Fig. 2).

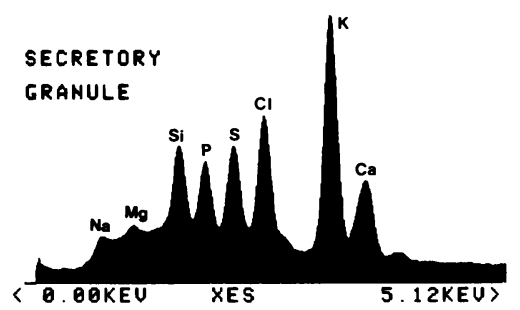

Figure 2. An x-ray spectrum obtained from a secretory granule in an acinar cell of the human labial gland. The Si peak is an artifact resulting from sample preparation and/or signal detection.
Computed elemental concentrations in secretory granules are presented in Table II.

$C F$ vs. control secretory granules. Comparisons of elemental concentrations in secretory granules from control- and CFaffected glands using different statistical methods yielded different findings. Significant CF-related increases in $\mathrm{Na}, \mathrm{K}, \mathrm{Cl}$, and $\mathrm{S}$ concentrations but not in $\mathrm{Ca}$ concentration were obtained with the linear contrast in the one way analysis of variance $(P$ $=0.001,0.001,0.003,0.001$, and 0.001 , respectively) and the Mann-Whitney $U$ over all values $(0.0001,0.001,0.001,0.0001$, and 0.0001 , respectively). However, only the increase in $\mathrm{Na}$ concentration was significant by the $t$ test and Mann-Whitney $U$ test of means of means ( $P=0.03$ and 0.05 , respectively). A disease-related decrease in $\mathrm{Ca} / \mathrm{S}$ ratio significant at the $P$ $\leq 0.05$ level was detected by all tests (for controls, $\mathrm{Ca} / \mathrm{S}$ $=0.22 \pm 0.02(\mathrm{SEM})$; for $\mathrm{CFs}, \mathrm{Ca} / \mathrm{S}=0.16 \pm 0.02$ : values are means of the means from each subject). 
Table II. Elemental Concentrations in Secretory Granules of Labial Glands from Control Subjects and Patients with CF

\begin{tabular}{|c|c|c|c|c|c|c|}
\hline \multirow[b]{2}{*}{ Subject } & \multirow[b]{2}{*}{$N$} & \multirow[b]{2}{*}{$\mathrm{Na}$} & \multicolumn{2}{|c|}{ Elemental concentrations* } & \multirow[b]{2}{*}{$\mathrm{Ca}$} & \multirow[b]{2}{*}{$\mathbf{s}$} \\
\hline & & & $\mathbf{K}$ & $\mathrm{Cl}$ & & \\
\hline & & & $m M / k g$ dry mass & $m M / k g$ dry mass & & \\
\hline \multicolumn{7}{|l|}{ Controls } \\
\hline 1 & 2 & $47 \pm 2^{*}$ & $408 \pm 52$ & $152 \pm 38$ & $71 \pm 2$ & $236 \pm 4$ \\
\hline 2 & 9 & $49 \pm 17$ & $325 \pm 61$ & $68 \pm 26$ & $88 \pm 17$ & $184 \pm 44$ \\
\hline 3 & 6 & $34 \pm 9$ & $200 \pm 56$ & $61 \pm 11$ & $70 \pm 26$ & $192 \pm 48$ \\
\hline 4 & 5 & $42 \pm 11$ & $325 \pm 68$ & $70 \pm 39$ & $86 \pm 14$ & $212 \pm 44$ \\
\hline 5 & 10 & $35 \pm 24$ & $221 \pm 177$ & $104 \pm 61$ & $116 \pm 63$ & $408 \pm 168$ \\
\hline$\overline{\mathrm{X}} \pm$ SEM $\ddagger$ & & $41 \pm 3$ & $296 \pm 38$ & $91 \pm 17$ & $86 \pm 8$ & $248 \pm 40$ \\
\hline \multicolumn{7}{|c|}{ CF patients } \\
\hline 6 & 7 & $119 \pm 192$ & $377 \pm 142$ & $166 \pm 128$ & $52 \pm 31$ & $176 \pm 76$ \\
\hline 7 & 11 & $47 \pm 13$ & $377 \pm 77$ & $99 \pm 53$ & $84 \pm 17$ & $304 \pm 40$ \\
\hline 8 & 12 & $110 \pm 40$ & $189 \pm 77$ & $71 \pm 26$ & $79 \pm 21$ & $344 \pm 56$ \\
\hline 9 & 9 & $44 \pm 13$ & $431 \pm 85$ & $144 \pm 36$ & $95 \pm 16$ & $436 \pm 56$ \\
\hline 10 & 6 & $119 \pm 45$ & $371 \pm 79$ & $176 \pm 58$ & $54 \pm 13$ & $288 \pm 124$ \\
\hline 11 & 15 & $73 \pm 33$ & $442 \pm 128$ & $165 \pm 57$ & $104 \pm 58$ & $416 \pm 200$ \\
\hline$\overline{\mathrm{X}} \pm \mathrm{SEM}$ & & $86 \pm 14$ & $371 \pm 38$ & $137 \pm 17$ & $78 \pm 8$ & $328 \pm 40$ \\
\hline$P(t) \S$ & & 0.03 & NS & NS & NS & NS \\
\hline
\end{tabular}

* Means \pm SD for each subject. $¥$ Means of means \pm SEM. $\S$ Significance level for $t$ test between mean of means from controls and patients with CF.

Tests for systematic differences between groups. Comparison of Chi square for curve-fitting, magnification, $\mathrm{Cu}$ and $\mathrm{Si}$ concentrations, and the ratio of film continuum to total continuum counts yielded several significant differences between control and CF groups. However, none of the elemental concentrations were significantly correlated with these parameters. Thus, intergroup differences in these parameters did not account for the observed disease-related differences in secretory granule elemental concentrations and concentration ratio.

Correlation of secretory granule elemental concentrations with disease severity. There were no strong correlations between the elemental concentrations in secretory granules and disease severity. $\mathrm{S}, \mathrm{Cl}$, and $\mathrm{K}$ concentrations were significantly correlated with Taussig score $(P=0.01)$, but the regressions only accounted for $10-32 \%$ of the observed variations in results.

Mass loss. Little or no mass loss was detected for doses between $2.6 \times 10^{-4}$ to $4.5 \times 10^{-3} \mathrm{C} / \mathrm{cm}^{2}$. Between $4.5 \times 10^{-3}$ and $1.0 \mathrm{C} / \mathrm{cm}^{2}$, there was an $\sim 40 \%$ mass (i.e., continuum count) loss. At higher doses, there was no further loss. S counts decreased in a similar fashion as the continuum counts, but the final amount of $\mathrm{S}$ loss was $75 \%$. No significant elemental losses were detected for $\mathrm{Na}, \mathrm{Cl}, \mathrm{K}$, or $\mathrm{Ca}$. Since all spectra were obtained with exposures $>1.0 \mathrm{C} / \mathrm{cm}^{2}$, the calculated concentrations were adjusted accordingly.

Findings in cytoplasmic and nuclear spaces. No significant disease-related differences in elemental concentrations were detected in cytoplasmic and nuclear spaces by the tests of means of means (Table III).

Significant intracellular differences were found in elemental concentrations of control cells (Table III). $\mathrm{K}$ concentrations in all three organelles were significantly different from one another, while $\mathrm{Ca}, \mathrm{Cl}$, and $\mathrm{S}$ concentrations in secretory granules were significantly different from those in cytoplasm and nuclei.

\section{Discussion}

Interpretation of $C F$ results. The present results indicate that secretory granules in labial glands from patients with CF tested under nonstimulated conditions had significantly different elemental concentrations from control glands: $\mathrm{Na}$ concentration was significantly elevated, and the ratio of $\mathrm{Ca} / \mathrm{S}$ was significantly decreased. On the average, Na concentration in CF secretory granules was about twice that in controls (Table II), while the $\mathrm{Ca} / \mathrm{S}$ ratio decreased by $\sim 25 \%$. The most likely interpretation of the latter finding is that the ratio decreased because $S$ concentration increased, as indicated by the linear contrast and Mann-Whitney results. The fact that the tests of means of means detected a statistically significant difference for the $\mathrm{Ca} / \mathrm{S}$ concentration ratio but not for the $\mathrm{Ca}$ and $\mathrm{S}$ concentrations themselves probably reflects the increased precision inherent in the concentration ratios. Use of such ratios rendered the results independent of two factors that contribute to the variability in the absolute concentrations: estimation of continuum counts and estimation of film continuum. Absolute concentrations were proportional to elemental counts divided by the term (total continuum counts minus film counts), while the concentration ratio was equal to the ratio of elemental counts alone.

The fact that a significant $\mathrm{CF}$-related difference in $\mathrm{Na}$ concentration was detected in secretory granules but not in cytoplasm nor in nuclei (Table III) suggests a site-specific lesion. 


\begin{tabular}{|c|c|c|c|c|c|}
\hline \multirow[b]{2}{*}{ Compartments subjects } & \multirow[b]{2}{*}{$\mathrm{Na}$} & \multicolumn{2}{|c|}{ Elemental concentrations ${ }^{*}$} & \multirow[b]{2}{*}{$\mathrm{Ca}$} & \multirow[b]{2}{*}{$\mathbf{s}$} \\
\hline & & $\mathbf{K}$ & $\mathrm{Cl}$ & & \\
\hline & & $\mathrm{mM} / \mathrm{kg}$ dry mass & $\mathrm{mM} / \mathrm{kg}$ dry mass & & \\
\hline \multicolumn{6}{|l|}{ Secretory granules } \\
\hline Controls $(n=32)$ & $41 \pm 3$ & $296 \pm 38$ & $91 \pm 17$ & $86 \pm 8$ & $248 \pm 40$ \\
\hline CF $(n=60)$ & $86 \pm 14$ & $371 \pm 38$ & $137 \pm 17$ & $78 \pm 8$ & $328 \pm 40$ \\
\hline$P \ddagger(1$ vs. 2$)$ & 0.03 & NS & NS & NS & NS \\
\hline \multicolumn{6}{|l|}{ Cytoplasm } \\
\hline Controls $(n=35)$ & $59 \pm 11$ & $544 \pm 16$ & $137 \pm 9$ & $18 \pm 4$ & $56 \pm 32$ \\
\hline $\mathrm{CF}(n=54)$ & $85 \pm 40$ & $542 \pm 43$ & $122 \pm 7$ & $17 \pm 3$ & $88 \pm 20$ \\
\hline$P \ddagger(1$ vs. 2$)$ & NS & NS & NS & NS & NS \\
\hline \multicolumn{6}{|l|}{ Nucleus } \\
\hline Controls $(n=36)$ & $59 \pm 10$ & $671 \pm 17$ & $133 \pm 8$ & $5 \pm 1$ & $36 \pm 8$ \\
\hline $\mathrm{CF}(n=43)$ & $95 \pm 41$ & $670 \pm 56$ & $134 \pm 8$ & $7 \pm 1$ & $44 \pm 8$ \\
\hline$P \nsucceq(1$ vs. 2$)$ & NS & NS & NS & NS & NS \\
\hline \multicolumn{6}{|c|}{$\begin{array}{l}\text { Interorganelle differences } \\
\text { by Duncan's test }\end{array}$} \\
\hline Controls & $\mathrm{S}, \mathrm{C}, \mathrm{N} \S$ & $\mathrm{S} / \mathrm{C} / \mathrm{N}$ & $\mathrm{S}, \mathrm{C}, \mathrm{N}$ & $\mathrm{S} / \mathrm{C}, \mathrm{N}^{\prime \prime}$ & $\mathrm{S} / \mathrm{C}, \mathrm{N}$ \\
\hline
\end{tabular}

* Values are means of means for each patient \pm SEM. ‡ Significance level for $t$ test between mean of means from controls and patients with CF. $\S$ No significant differences between secretory granules $(\mathrm{S})$, cytoplasm $(C)$, and nuclei $(\mathrm{N})$. " $\mathrm{S}$ significantly different from $\mathrm{C}$ and $\mathrm{N}$.

All of the above findings are independent of the mass loss incurred by the present samples, provided only that mass loss was equal in control and CF sections.

General findings. It is not possible to definitely know which types of acinar cells were sampled in the present study because mucous cells are not so easily distinguished from serous cells in unstained freeze-dried cryosections as they are in stained sections at the light level. However, serous cells in cryosections prepared from rat parotid glands characteristically contain many dense secretory granules (14), while the cells included in this study contained only a few granules. In addition, we observed by light microscopy that mucous cells greatly outnumber serous cells. This is consistent with the earlier report by Tandler et al. (1) that human labial glands contain only mucous acini. These considerations make it most likely that the present concentrations are representative of those in mucous acinar cells. If this is the case, then the secretory granules included in this study were mucous granules. Similar secretory granules were previously described in mucous cells in freezedried cryosections of $\mathrm{dog}$ and rat submandibular glands $(15,16)$.

The fact that duct cells were not observed in the present cryosections can be explained by the sectioning strategy. Because freeze damage increases with depth, the present sections were obtained from the outermost surfaces of the gland fragments, and such surfaces consist primarily of acinar units.

Normal intracellular concentration differences. The present findings in normal human labial gland acinar cells that the concentration of $\mathrm{Ca}$ in secretory granules is significantly higher than cytoplasmic and nuclear concentrations is consistent with previous microprobe studies of mucous granules from submandibular glands in other species $(15,16)$. The present finding that $\mathrm{K}$ concentration was higher in nuclei than in cytoplasm or secretory granules is consistent with a previous microprobe report in rabbit smooth muscle (17). The difference in $\mathrm{K}$ concentrations cannot be accounted for by hydration differences since no significant difference was found between nuclear and cytoplasmic dry mass contents $(67,121 \pm 9,164$ vs. 62,508 $\pm 9,634$ ).

Relevance to $C F$. Our results indicate that the $\mathrm{Na}$ content of labial gland secretory granules was elevated in CF, and this may be of pathophysiological significance. Tam and Verdugo (6) showed the unfolding of mucus to be dependent on cation concentration, with higher concentrations resulting in less unfolding and a denser configuration. Thus, the increased $\mathrm{Na}$ concentrations observed in the present CF secretory granules may cause CF mucin to undergo less unfolding after exocytosis into the acinar lumen. Such a configuration could make the mucin difficult to clear, leading to possible formation of mucin plugs at the level of acinar or intercalated duct lumen. It is interesting to note that such plugs are frequently observed at the acinar level of labial glands from patients with CF (4). This scenario would be independent of any disease-related changes in ionic resorption capabilities of the more distal ductal elements $(18,19)$.

The present results also suggest that labial saliva mucins would be more heavily sulfated in CF. This prediction remains to be tested in labial saliva, but findings suggestive of increased sulfation have been made with other CF mucins $(5,20-22)$. A particularly convincing demonstration is that of Boat et al. (5) who found a shift to the secretion of more highly acidic mucous glycoprotein compounds in CF tracheal-bronchial mucin. Although they did not test their results for statistical significance, application of the Mann-Whitney rank test to the results in their Fig. 4 shows the difference between patients with CF and those with conducting airway disease to be significant at the 0.01 level. Since the more highly acidic components also had higher sulfate levels (their Table III), it 
follows that the mucins are also significantly more highly sulfated. Boat et al. argue that such sulfation changes could also affect the rheological properties of CF mucin.

The present findings indicate that the elemental concentration differences reported here are not significantly correlated with disease severity. Although statistically significant correlations were obtained between $\mathrm{S}, \mathrm{Cl}$, and $\mathrm{K}$ concentrations and Taussig score, the correlation coefficients were small $(r=0.29$, 0.45 , and 0.58 , respectively), and explained at most only $34 \%$ of the variance in the $K$ results.

Comparison with previous parotid gland results. The present results in human labial glands (Table III) contrast with results reported earlier for human parotid glands, where glandular $\mathrm{Na}$ and $\mathrm{Ca}$ concentrations were significantly increased and $\mathrm{K}$ concentration decreased (7). One possible explanation for the difference in findings is that the previous differences arose from an inability to precisely control time after death when different samples were obtained. However, another possibility is that the concentration changes are unique to severely ill patients, since all of the patients in the previous study had succumbed to complications of CF. This latter possibility is supported by our observation that the most severely affected patient in the present study had cytoplasmic elemental concentration changes identical to those previously reported for the parotid (7). Thus, further work will be required to establish whether significant cytoplasmic elemental concentration changes occur in severely affected patients with $\mathrm{CF}$.

\section{Acknowledgments}

This work was supported by National Institutes of Health grants R03DE06487 and R01DE06373.

\section{References}

1. Tandler, B., C. R. Denning, I. D. Mandel, and A. H. Kutscher. 1969. Ultrastructure of human labial salivary glands. I. Acinar secretory cells. J. Morphol. 127:383-408.

2. Weismann, U. N., T. F. Boat, and P. A. di Sant Agnese. 1972. Flow-rates and electrolytes in minor salivary gland saliva in normal subjects and patients with cystic fibrosis. Lancet. II:510-512.

3. Doggett, R. G., B. Bentinck, and G. M. Harrison. 1971. Structure and ultrastructure of the labial salivary glands in patients with cystic fibrosis. J. Clin. Pathol. (Lond.). 24:270-282.

4. Sweney, L. R., and W. J. Warwick. 1967. The involvement of the labial salivary gland in patients with cystic fibrosis. III. Ultrastructural changes. Arch. Pathol. 86:413-418.

5. Boat, T. F., P. W. Cheng, and R. E. Wood. 1977. Tracheobron- chial mucus secretion in vivo and in vitro by epithelial tissues from cystic fibrosis and control subjects. Mod. Probl. Paediatr. 19:141-152.

6. Tam, P. Y., and P. Verdugo. 1981. Control of mucus hydration as a Donnan equilibrium process. Nature (Lond.). 292:340-342.

7. Mangos, J. A., and W. H. Donnally. 1981. Isolated parotid acinar cells from patients with cystic fibrosis. Morphology and composition. J. Dent. Res. 60:19-26.

8. Taussig, L. M., J. Kattwinkel, W. T. Friedewald, and P. A. di Sant Agnese. 1973. A new prognostic score and clinical evaluation system for cystic fibrosis. J. Pediatr. 82:380-390.

9. Shuman, H., A. U. Somlyo, and A. P. Somlyo. 1976. Quantitative electron probe microanalysis of biological thin sections: methods and validity. Ultramicroscopy. 1:317-339.

10. Hall, T. A., H. C. Anderson, and T. Appleton. 1973. The use of thin specimens for X-ray microanalysis in biology. J. Microsc. (Oxf.). 99:177-182.

11. Siegel, S. 1956. Nonparametric Statistics for the Behavioral Sciences. McGraw-Hill, Inc., New York, p. 116.

12. Roomans, G. M., O. Ceder, and H. Kollberg. 1981. Electrolyte redistribution in cystic fibrosis fibroblasts studied by electron probe $\mathrm{X}$ ray microanalysis. Ultrastruct. Pathol. 2:53-58.

13. Nie, N. H., C. H. Hull, J. G. Jenkins, K. Steinbrenner, and D. H. Bent. 1975. SPSS Statistical Package for the Social Sciences. McGraw-Hill, Inc., New York. Second ed. 675 pp.

14. Izutsu, K. T., D. E. Johnson, E. S. Wang, A. Tamarin, W. Y. Ensign, and M. K. Goddard. 1983. Microbeam analysis of resting rat parotid gland. Proc. Annu. Conf. Microbeam Analysis Soc. 18:257258.

15. Roomans, G. M., X. Wei, O. Ceder, and H. Kollberg. 1982. The reserpinized rat in the study of cystic fibrosis-X-ray microanalysis of submandibular gland and pancreas. Ultrastruct. Pathol. 3:285-293.

16. Sasaki, S., I. Nakagaki, H. Mori, and Y. Imai. 1983. Intracellular calcium store and transport of elements in acinar cells of the salivary gland determined by electron probe X-ray microanalysis. Jpn. J. Physiol. 33:69-83.

17. Somlyo, A. P., A. V. Somlyo, and H. Shuman. 1979. Electron probe analysis of vascular smooth muscle. J. Cell Biol. 81:316-335.

18. Quinton, P. M., and J. Bijman. 1983. Higher bioelectric potentials due to decreased chloride absorption in the sweat glands of patients with cystic fibrosis. N. Engl. J. Med. 308:1185-1189.

19. Knowles, M., J. Gatzy, and R. Boucher. 1981. Increased bioelectric potential difference across respiratory epithelia in cystic fibrosis. N. Engl. J. Med. 305:1489-1495.

20. Lamb, D., and L. Reid. 1972. The tracheobronchial submucosal glands in cystic fibrosis: a qualitative and quantitative histochemical study. Br. J. Dis. Chest. 66:239-247.

21. Wesley, A., J. Forstner, R. Qureshi, M. Mantle, and G. Forstner. 1983. Human intestinal mucin in cystic fibrosis. Pediatr. Res. 17:65-69.

22. Frates, R. C., Jr., T. T. Kaizu, and J. A. Last. 1983. Mucous glycoproteins secreted by respiratory epithelial tissue from cystic fibrosis patients. Pediatr. Res. 17:30-34. 